\title{
Clinical Factors Associated with Cutaneous Cerebrospinal Fluid Leakage in Infants Who Underwent a Ventriculoperitoneal Shunt Surgery
}

\section{Fatores clínicos associados a fístula liquorica cutânea em lactentes submetidos a derivação ventriculoperitoneal}

\author{
Andrea Silva de Pinho ${ }^{1}$ Fábio Cunha de Almeida ${ }^{1}$ Felipe Bicalho Maluf ${ }^{1}$ Ivana Duval-Araujo ${ }^{2}$ \\ ${ }^{1}$ Neurosurgeon, Pediatric Neurosurgery Service, Odilon Behrens \\ Municipal Hospital, Belo Horizonte, MG, Brazil \\ ${ }^{2}$ Surgeon, Department of Surgery, Medical School, Universidade \\ Address for correspondence Andréa Silva de Pinho, MD, Av. dos \\ Bandeirantes 1067/601. Anchieta. Belo Horizonte, MG, Brazil, CEP \\ 30315-000 (e-mail: andrea.pinho.neurocirurgia@gmail.com).
} Federal de Minas Gerais, Belo Horizonte, MG, Brazil

Arq Bras Neurocir 2015;34:7-12.

\section{Abstract \\ Keywords \\ - hydrocephalus \\ - wound healing \\ - ventriculoperitoneal shunt}

\section{Resumo}

Objective The aim of the study is to determine the factors related to fetal maturity and clinical parameters that may be involved in the development of skin cerebrospinal fluid leakage.

Methods This study evaluated 72 infants undergoing ventriculoperitoneal (VP) shunt between 2004 and 2008 at the Odilon Behrens Municipal Hospital. All children were treated by the same surgeon, and the clinical data concerning weight, age, and percentile, as well as hemoglobin levels, were collected from medical records and duly noted in proper protocols.

Results A tendency toward a high incidence of fistula could be observed in children born with a weight percentile of less than $10(p=0.06)$, and an even higher incidence could be identified in children who underwent surgery before 1 month of life $(p<0.05)$. Other parameters showed no significant difference in the comparison between children with and without cerebrospinal leakage.

Conclusion The chronological age and the degree of intrauterine nutrition are determining factors in cerebrospinal fluid leakage in infants and may well influence the incidence of wound complications after a VP shunt.

Objetivos Determinar fatores clínicos e de maturidade fetal que possam estar envolvidos no desenvolvimento de fístulas cutâneas pós-operatórias.

Métodos Foram avaliados 72 lactentes submetidos a derivação ventriculoperitoneal no Hospital Municipal Odilon Behrens no período de 2004 a 2008. Os dados clínicos e received

August 28, 2014

accepted

November 1, 2014
DOI http://dx.doi.org/

10.1055/s-0035-1547380. ISSN 0103-5355.
Copyright ๑ 2015 Thieme Publicações

Ltda, Rio de Janeiro, Brazil
License terms

(ㄷ) (i) $\ominus$ (5) 
Palavras-chave

- hidrocefalia

- cicatrização

- derivação ventriculoperitoneal laboratoriais ao nascimento e à cirurgia foram coletados dos prontuários e anotados em protocolos próprios.

Resultados Houve uma tendência a ocorrência de fístulas em crianças nascidas com percentil de peso abaixo de $10(p=0,06)$ e maior incidência em crianças operadas antes de um mês de vida $(p<0,05)$. Os demais parâmetros não foram significativos. Conclusão A idade cronológica e o grau de nutrição intrauterina são fatores envolvidos na formação de fístulas liquóricas em recém-nascidos, tendo impacto na prevalência de complicações nas feridas de lactentes submetidos a derivação ventriculoperitoneal.

\section{Introduction}

Hydrocephalus is the most frequent complaint in pediatric neurosurgery and is commonly associated with other congenital disorders, brain tumors, head trauma, intraventricular hemorrhage caused by premature birth, spontaneous cerebral hemorrhage, or infection within the central nervous system. Most children, especially less than 6 months age, are treated with ventriculoperitoneal (VP) shunts, which can be linked to various complications, including a rate of failure or dysfunction of $40 \%$ and a rate of infection of 0.3 to $30 \%$.,2

Shunt infection occurs in the first few months after surgery, with a significant risk of morbidity, including seizures and cognitive decline. Treatment of infections requires the removal of the bypass system, the implementation of temporary external shunts or periodic relief stamps, the use of antibiotics, and the replacement of the shunt system, which involves a minimum of two surgeries and 3 to 4 weeks of hospitalization. In addition, this process incurs the risk of a long-term mortality of $30 \%$, twice that found in children with no infections. 3,4

Several risk factors for infection have been identified in the literature, including diseases that cause hydrocephalus, chronological age, gestational age, birth weight and surgery, presence of prior shunt, patient's skin colonization, duration of surgery, holes in surgical gloves, cerebrospinal fluid leakage to skin, or postoperative collection of the fluid within the subcutaneous tissue. ${ }^{1-3}$ The lack of consensus about the major factor associated with an increase in infection caused by a VP shunt may well be due to the wide range of applied methodologies and the absence of randomized trials. ${ }^{1,3,5-7}$

A cerebrospinal cutaneous fistula is a relatively rare complication that most commonly occurs after a VP shunt surgery. This fistula is most usually found in cranial wounds, and its major clinical sign is the discharge of "fluid" through the skin, which provides communication between the external environment and the central nervous system. The reported frequency varies from 0 to $6.8 \%$, appearing on average for 4.9 postoperative days (ranging from 1 to 13 days), and is a factor that has proven to be associated with infections of the central nervous system, increasing in up to 27 times its normal frequency of infections. ${ }^{1,3-7}$

The cerebrospinal fistula (CSF) has been described with greater frequency in children younger than 6 months. ${ }^{6}$ Some authors associate the CSF with mechanical dysfunction, obstruction, or disconnection of the shunt system. If the system is patent, only a very small difference between the ventricular and abdominal pressure in children can be observed, in addition to the presence of fontanelle and open sutures, which would be insufficient to open and drain valves, thus accumulating fluid in the subcutaneous tissue. The short distance between the opening of the dura mater and the ventricle produced by the extreme enlargement of the ventricular system, by means of a small cortical mantle, decreases the path that the fluid travels through the subcutaneous tissue. In addition, the formation of a large dural aperture during the surgical procedure, excess subcutaneous dissection of the thin skin, and high-pressure valves also bring into question whether or not the development of fistulas could represent a marker of poor wound healing. 3,6,7

To prevent leakage in children younger than 6 months, low-pressure or programmable valves were used, in addition to a minimal incision and dural aperture, a frontal burr hole, a dural placement of the catheter in a region containing the largest portion of the cerebrum, and postoperative positioning with the head raised. ${ }^{5,6}$

Through clinical observation, it could be noted that the postoperative CSF occurs with greater frequency in preterm and underweight children. However, it is necessary to establish a scientific foundation based on important data from clinical practices in an attempt to determine which associated clinical factors can be avoided and aid in establishing methods to prevent this complication.

\section{Patients and Methods}

This retrospective study was submitted to the Research Ethics Committee of the Odilon Behrens Municipal Hospital and approved under protocol number 0011.0.216.000-09. This study included children younger than 2 years with a diagnosis of hydrocephalus treated at Odilon Behrens Municipal Hospital between 2004 and 2008. All children were treated by means of VP shunt performed by the same surgeon.

This study included children younger than 2 years with a weight of more than $1.75 \mathrm{~kg}$ and those who have undergone the first surgery. Excluded from this study were children with incomplete records, who were 2 years of age or older, who were subject to a repeat operation, whose surgery was 
performed by another surgeon, or whose surgery used another type of hydrocephalus valve.

To complete the operation, a drainage valve of the same model and pressure (Codman, neonatal, low pressure) was used. The wounds showed no signs of infection, and no infection had been diagnosed before the leakage occurred.

Of 123 children who underwent surgery, 72 met the predefined criteria. Data were evaluated regarding the period of birth and the time of surgery. The data recorded at birth were gestational age, weight, and weight percentile. Weight and weight percentile were used as references of nutritional status due to the ease through which the data were obtained, the small margin of measurement error, and this admittedly isolated measurement parameter for this type of review.

The data evaluated during surgery included chronological age, weight, weight percentile, and hemoglobin. The weight percentile was calculated by the intrauterine growth curve for premature children (26-37 weeks) and the postnatal growth curve in term children. ${ }^{8,9}$

Because of the wide dispersal and observed standard deviation in parameters, the children were divided into groups according to each analysis.

To analyze the relationship between gestational age at birth and the occurrence of CSF, children were divided into group 1, children with less than 30 weeks' gestation; group 2 , between 30 and 35 weeks; and group 3, with more than 35 weeks. To analyze the relationship between birth weight and presence of fistula, the following groups were established: group 1, for children weighing less than $1.5 \mathrm{~kg}$; group 2 , between 1.5 and $2.5 \mathrm{~kg}$; and group 3, with more than $2.5 \mathrm{~kg}$. To analyze the relationship between the weight percentile and the development of fistulas, the children were divided into group 1, weight percentile of less than 10; group 2, between 10 and 25; and group 3, greater than 25.

To analyze the variables at the time of surgery, assessing the relationship between chronological age and the development of fistulas, the children were divided into group 1 , consisting of children who had undergone surgery with less than 1 month of age; group 2, those who had undergone surgery with 1 to 6 months of age; and group 3, those who had undergone surgery with more than 6 months of age. With regard to weight, the children were divided into group 1, children weighing less than $2 \mathrm{~kg}$; group 2, between 2 and $5 \mathrm{~kg}$; and the group 3, more than $5 \mathrm{~kg}$. To analyze the weight percentile at the time of surgery and the formation of fistulas, the children were divided into group 1, children with a percentile value of less than 10; group 2, with percentile values of between 10 and 25; and group 3, with percentile values of greater than 25 .

The data were compared regarding the occurrence of fistulas in the previously described groups by means of chi-square tests for qualitative variables and the Student $t$-test for quantitative variables.

\section{Results}

Prematurity, less than 30 weeks of gestational age, was diagnosed in 21 children with a one developed fistula
(4.8\%). Another 15 premature children, between 30 and 35 weeks of gestational age, were diagnosed with four developed fistulas (26.7\%). In children with more than 35 weeks of gestational age, 36 patients underwent surgery, 3 of whom were diagnosed with fistulas (8.3\%). Despite the higher incidence of fistulas in children born between 30 and 35 weeks of gestational age, no significant difference among the groups could be observed.

Upon analyzing the data, the average gestational age at birth was $29.0 \pm 3.0$ weeks in the group with fistulas and $29.7 \pm 2.8$ weeks in the group in which no fistula formation could be identified.

The average weight of the children at birth was $2.09 \pm 1.03 \mathrm{~kg}$ in children with fistulas and $2.19 \pm 1 \mathrm{~kg}$ in children without fistulas. Of the 72 children, 29 were born weighing less than $1.5 \mathrm{~kg}, 3$ of whom (10.3\%) presented fistulas. Of the eight children weighed between 1.5 and $2.5 \mathrm{~kg}$, none were diagnosed with developed fistulas. By contrast, Of the 35 children were born with a weight of more than $2.5 \mathrm{~kg}, 5$ (14.3\%) were diagnosed with developed fistulas. No significant difference could be observed when comparing the evaluated groups.

Considering data regarding the weight percentile at birth, 14 of the children presented a weight percentile of less than 10 , three of whom (21.4\%) were diagnosed with fistulas. Another 17 children were born with a weight percentile of between 10 and 25, only 1 of whom (5.9\%) developed a fistula. Likewise, 41 children were born with a weight percentile of greater than 25,4 of whom (9.8\%) were diagnosed with developed fistulas. Therefore, the greatest tendency of developed fistulas could be observed in children with a weight percentile of less than $10(p=0.06)$, as can be seen in - Fig. 1.

Upon analyzing the data of the chronological age at the time of surgery, the average age of the children was $4.4 \pm 5.5$ months, considering $3.6 \pm 3.7$ months in the group in which developed fistulas were diagnosed, as compared with $4.7 \pm 6.0$ months in the group in which no fistulas could be identified. Of the 72 children evaluated, 13 underwent surgery at less than 1 month of age, 3 of whom (23.1\%) were diagnosed with fistulas. By contrast, 45 children between 1

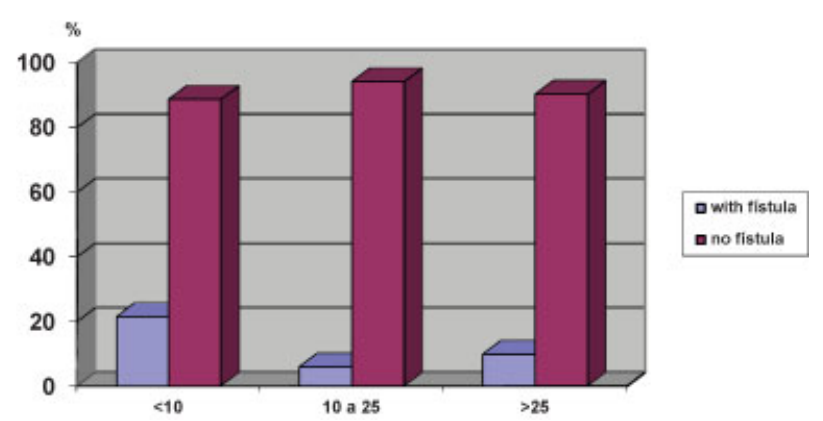

Fig. 1 Distribution of 72 children with a weight percentile of less than 10 , between 10 and 25, and more than 25, upon birth, who had developed or not a fistula after a ventriculoperitoneal shunt performed between 2004 and 2008 at the Odilon Behrens Municipal Hospital. 


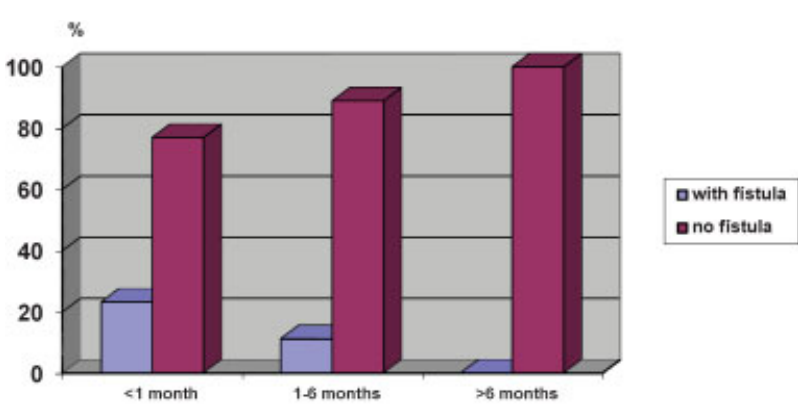

Fig. 2 Distribution of 72 children younger than 1 month, between 1 and 6 months, and older than 6 months at the time of surgery and who had developed or not a fistula after a ventriculoperitoneal shunt performed between 2004 and 2008 at the Odilon Behrens Municipal Hospital.

and 6 months of age underwent surgery, 5 of whom (11.1\%) were diagnosed with fistulas, and 14 children older than 6 months underwent surgery, but no fistulas could be identified. Significant increase could be observed in the incidence of fistulas in children who underwent surgery at less than 1 month of age when compared with those with more than 6 months of age $(p=0.05)$. In all children, the fistulas occurred before 6 months of age (-Fig. 2).

The average weight of the children at the time of surgery was $4.5 \pm 2.9 \mathrm{~kg}$. Children who had developed fistulas presented an average weight of $4.13 \pm 3.07 \mathrm{~kg}$, whereas those without fistulas presented an average weight of $4.63 \pm 2.81 \mathrm{~kg}$. The average weight of the children at the time of surgery showed no significant difference among the groups. In the present study, nine children, weighing less than $2.0 \mathrm{~kg}$, underwent surgery, only one of whom (11.1\%) presented a developed fistula. By contrast, 44 children, weighing between 2.0 and $5.0 \mathrm{~kg}$, underwent surgery, 6 of whom (13.6\%) presented a developed fistula, and 19 children, weighing more than $5.0 \mathrm{~kg}$, underwent surgery, only 1 of whom (5.3\%) presented a developed fistula.

At the time of surgery, 28 children presented a weight percentile of less than 10,4 of whom (14.3\%) presented a developed fistula. By contrast, 7 children were classified with weight percentiles of between 10 and 25,1 of whom (14.3\%) presented a developed fistula; whereas another 37 children were classified with a weight percentile of greater than 25,3 of whom (8.1\%) presented developed fistulas. No significant differences could be observed among the groups.

At the time of surgery, the average hemoglobin level was measured at $10.5 \pm 1.8 \mathrm{~g} / \mathrm{dL}$, with $10.7 \pm 1.3 \mathrm{~g} / \mathrm{dL}$ in patients with fistulas and $10.4 \% \pm 1.8 \mathrm{~g} / \mathrm{dL}$ in those without fistulas.

\section{Discussion}

The children evaluated in the present work were operated on by the same surgeon at the same hospital, fell under the same populational group, and were analyzed by a same preoperative group of professionals. In addition to fulfilling that set forth in the release procedure act regarding surgical risk, the only other limiting factor for surgery was each child's weight. All children undergoing surgery should have a minimum weight of more than $1.75 \mathrm{~kg}$, as defined by prior literature, in which there is a lesser incidence of clinical and surgical complications, particularly about skin infections. All valves used for drainage of hydrocephalus were purchased from the same manufacturer, containing the same characteristics and were functioning properly when fistulas occurred. No infection or wound dehiscence could be observed. Moreover, no immediate complications regarding the use of low-pressure valves, such as the hyperdrainage of fluid, the thrusting open of sutures, or subdural hematomas, could be observed.

The cerebrospinal fluid leakage from the first to the 43rd child occurred postoperatively. These children were treated by elevating the headboard and implementing a new nylon wound suture in continuous stitches and by placing synthetic glue above the stitches. Five of these were fistulas in scalp wounds and three in abdominal wounds. None of the fistulas was preceded by the collection of subcutaneous tissue.

The concentration of fistulas in newborn children, even when belonging to the same group, led to the study of the factors that could be involved in healing at this age.

Most fistulas occur before the complete epithelization of the wound, within an average time of 4.9 days, according to prior literature, and 12 days, in this case-by-case scenario. Furthermore, the fact that data from the literature cite a programmatic reduction in the drainage pressure of the fluid over a 10- to 14-day period until wound healing has occurred suggests the existence of a specific factor present in newborns that can alter healing. ${ }^{6,7}$ Most authors cite several factors to justify the fistula, such as less scarring. Recommendations for placing low-pressure valves to reduce the presence and stress of the fluid under the wound without question what would lead to fistula in some children.

The fistula is a well-known factor that triggers infections in the central nervous system and suggests a technical means to prevent its formation, which has been well-documented in prior literature. ${ }^{1,3,6,10,11}$ However, little information is available in the literature concerning its frequency, triggers, predisposition, or etiology. Therefore, understanding when fistulas occur and the factors that can influence a fistula in different age groups, such as children younger than 1 month and older than 6 months, in addition to underweight or underfed intrauterine newborns, was the focus of the present work. ${ }^{10-16}$

Some findings observed both in practice and in the literature demonstrate the involvement of healing in the formation of cerebrospinal fluid fistulas in infants, although findings concerning scarring in newborns and infants have been consistently more effective. ${ }^{1,6,8,9,13-17}$

It is possible that newborns and infants may possess specific factors that hinder fluid drainage, or that occur in excess, accumulating in the subcutaneous tissue or producing a hydraulic effect. Children with hydrocephalus typically have a small cerebral cortex, thus leaving a cerebral parenchyma mechanical barrier, which is essential to skin scarring and which produces a block to prevent cerebrospinal fluid leakage caused by the path created by the ventricular catheter inserted during surgery.

However, data suggest that the collection of subcutaneous fluid occurs in all age groups, at a frequency of up to $21.4 \%$, 
without excess leakage from the wound in most cases. $5,6,11,13,17$ In the present study, the fistulas occurred in children younger than 6 months, once again indicating that a change in the scarring factor may be involved.

In prior cases, the collection of subcutaneous fluid did not precede a fistula, discarding the possibility of hydraulic force causing a fistula.

Casuistry showed the presence of fistulas in the cranial and abdominal regions, which once again suggested that only structural and mechanical factors were involved in the formation of fistulas in infants. Moreover, by analyzing the etiology of hydrocephalus, it could be observed that none of the children with a developed fistula presented an absence of the cerebral mantle, which is characteristic of hydranencephaly.

Changes in healing can combine both morphological and functional complications in fistulas. Both systemic and local factors can affect the process of skin repair, including age and nutrition level.

The immaturity and thickness of the skin may well explain the presence of fistula groups only in children younger than 6 months.

To analyze the two main skin components-the dermis and the epidermis-the knowledge of the stages of development and maturation of this tissue is essential in treating newborn, especially preterm, infants. The epidermis begins its differentiation at 6 weeks of gestation and extends until the end of the gestational age. The differentiation of keratinocytes in the stratum corneum begins at 22 to 24 weeks, whereas at 28 weeks, the stratum corneum consists of two to three layers of cells. In the 32nd week, there are more than 15 layers of corneocytes, which is equivalent to an adult's skin. The dermis is composed of dense connective tissue. From the third to the fifth month of pregnancy, the number and size of the proteins from the matrix of the dermis increase, and the dermis continues its maturation until approximately 6 months after birth. No description can be found in the literature concerning the inflammatory response and stages of wound healing in this group of patients, nor regarding its relationship with the maturity of the skin or how premature skin matures.

Age is one of the most relevant aspects as it affects the functioning of all bodily physiological systems. Fetal wound healing is well-documented in the literature, especially about regeneration, characterized by its speed, absence of inflammatory response, absence of neovascularization, and scar. The mechanisms that regulate this difference are not yet defined. In the third trimester of pregnancy in animals, this process already occurs with the presence of a scar, similar to which occurs in adults. ${ }^{15,16}$ After birth, both qualitative and quantitative differences can be observed between young and old patients. In young patients, the wound heals more rapidly, the structural organization of the collagen fibers is better and more complex, and the restoration of the microvascular system occurs more quickly. In rabbits, fetuses heal more quickly than do newborns, which also heal more quickly than do adults. When compared with adults, young animals develop a resistance to wounds more quickly, demonstrating a more complex structural organization of the collagen. ${ }^{15,16}$ In addition, in newborn rats, as compared with adult rats, wound healing took place 10 to 12 times faster and with less of a scar in the connective tissue. ${ }^{17}$

Little information is available concerning fetal and postnatal scarring in human beings, mainly due to the difficulty in obtaining material in vivo, particularly in children. Some devices are placed on the wound for the biochemical evaluation of exudates, and the results of these studies tend to indicate that healing is faster at a lower age. ${ }^{18}$

In this study, it could be observed that gestational age was similar among the groups with and without fistulas, demonstrating that intrauterine maturity has not been an important factor in healing dynamics. However, surgery based on chronological age added an increased risk of the development of fistulas, which only occurred in groups of children up to 6 months of age, with a significantly greater frequency in children who had undergone surgery at less than 1 month of age. These data suggest that a specific factor contributes to the healing of disabilities at this age, most likely local factors, such as skin thickness and maturation. Another contributing factor is the fact that children at this age are kept in bed, with a more inappropriate positioning of the head for scalp wound compression. The pediatric surgeon, therefore, must take special care when dealing with sutures and postoperative wounds.

Another factor related to the healing of tissues is nutritional status. Malnutrition is closely associated with fistulas. Protein loss, reduced food intake, and hypercatabolism also contribute to this framework.

The children's weights before surgery were similar in the two groups and proved not to be related to failures in the healing process. The weight percentile at the time of surgery also proved not to contribute to differences in results. However, when examined for the weight percentile at birth, a tendency toward a higher incidence of fistulas could be observed in children born with a weight percentile of less than 10 (i.e., malnourished), which could indicate that intrauterine nutritional factors in fact interfere in wound healing. The effect of maternal malnutrition during pregnancy on birth weight is well known, but its consequences within the healing process have not been fully explored. Mice that were submitted to an intrauterine malnutrition after birth recovered their weight but still presented alterations in the healing process, with variations in tensile strength, in wound bursting strength, as well as in maximum resistance. Collagen deposition was similar among the studied groups. ${ }^{19}$ The result obtained from the data in this case seems to indicate that intrauterine nutritional factors may have interfered in the healing of wounds.

The fact that the present study found fistulas in children over a longer period than that reported in prior literature may well be related to the fact that the children came from low-income population groups and presented a higher prevalence of malnutrition.

The result obtained from the data in this case seems to indicate that nutritional factors may have interfered in the intrauterine healing of wounds. 
One single article in the literature could be found, which assessed the effect of the cerebrospinal fluid on the healing of the wound in mice. This article reported on the wounds regarding the neovascularization of small vessels, increased formation of mesenchymal tissue and granulation tissue reaction, smooth waxy fiber degeneration, and fat and ischemic necrosis, but without cerebrospinal fluid leakage from the wound. The present study did not observe cerebrospinal fluid leakage from the wound. In the control group, only a minimal invasion of lymphocytes could be observed in the subdermis area, and the formation of collagen and its arrangement in the suture line were normal in the two groups. The study demonstrated changes in the healing process when in the presence of cerebrospinal fluid under the wound, but no changes could be observed in its dynamics. ${ }^{20}$ In the same study, the authors questioned the role of the presence of this cerebrospinal fluid under the wound regarding the identified changes, which may well be due to its sodium content or hydraulic effect and glucose, which can provide a good medium for bacterial growth, or even on the edges of skin maceration. ${ }^{20}$

Hemoglobin levels analyzed in this study referred to the value before any blood transfusion had been performed, given that the children receive red blood cell concentrates of less than $10 \mathrm{~g} / \mathrm{dL}$ in the preoperative phase. In so doing, it was understood that the children could be evaluated as to the interference of anemia in the healing process. No significant difference could be observed among the groups regarding the formation of fistulas and hemoglobin levels.

\section{Conclusion}

In conclusion, there are apparently factors related to skin maturity and the level of intrauterine nutrition that can join the greater risk of the formation of cerebrospinal fluid fistulas in infants with hydrocephalus who underwent surgery for the placement of VP shunts. These data may prove useful in the planning of these types of surgeries for patients so as to reduce the incidence of postoperative complications, especially when performing surgery on children with more than 1 month of life.

\section{Conflict of Interest}

The authors declare no conflict of interest.

\section{References}

1 Jeelani NU, Kulkarni AV, Desilva P, Thompson DN, Hayward RD. Postoperative cerebrospinal fluid wound leakage as a predictor of shunt infection: a prospective analysis of 205 cases. Clinical article. J Neurosurg Pediatr 2009;4(2):166-169
2 Rotim K, Miklic P, Paladino J, Melada A, Marcikic M, Scap M. Reducing the incidence of infection in pediatric cerebrospinal fluid shunt operations. Childs Nerv Syst 1997;13(11-12): 584-587

3 Kulkarni AV, Drake JM, Lamberti-Pasculli M. Cerebrospinal fluid shunt infection: a prospective study of risk factors. J Neurosurg 2001;94(2):195-201

4 Campos AC, Branco AB, Matias JE, Campos LF. Nutritional therapy and digestive tract fistulas [in Spanish]. Acta Gastroenterol Latinoam 2007;37(2):118-125

5 Davis SE, Levy ML, McComb JG, Masri-Lavine L. Does age or other factors influence the incidence of ventriculoperitoneal shunt infections? Pediatr Neurosurg 1999;30(5):253-257

6 Rohde V, Weinzierl M, Mayfrank L, Gilsbach JM. Postshunt insertion CSF leaks in infants treated by an adjustable valve opening pressure reduction. Childs Nerv Syst 2002;18(12): 702-704

7 Korinth MC, Gilsbach JM. What is the ideal initial valve pressure setting in neonates with ventriculoperitoneal shunts? Pediatr Neurosurg 2002;36(4):169-174

8 Lubchenco LO, Hansman C, Boyd E. Intrauterine growth in length and head circumference as estimated from live births at gestational ages from 26 to 42 weeks. Pediatrics 1966;37(3): 403-408

9 Marques RM, Marcondes E, Berquo E, Prandi R, Yunes J. Crescimento e desenvolvimento pubertário em crianças e adolescentes brasileiros: altura e peso. São Paulo, Brazil: Brasileira de Ciências; 1982

10 Boop FA. Posthemorrhagic Hydrocephalus of prematurity. In: Cinalli G, Maixner WJ, Saint-Rose C, eds. Pediatric Hydrocephalus. Italy: Springer; 2004:121-131

11 Frim DM, Scott RM, Madsen JR. Surgical management of neonatal hydrocephalus. Neurosurg Clin N Am 1998;9(1):105-110

12 Sekhar LN, Moossy J, Guthkelch AN. Malfunctioning ventriculoperitoneal shunts. Clinical and pathological features. J Neurosurg 1982;56(3):411-416

13 Broughton G II, Janis JE, Attinger CE. Wound healing: an overview. Plast Reconstr Surg 2006;117(7, Suppl):1e-S-32e

14 Taylor AG, Peter JC. Advantages of delayed VP shunting in posthaemorrhagic hydrocephalus seen in low-birth-weight infants. Childs Nerv Syst 2001;17(6):328-333

15 Cass DL, Bullard KM, Sylvester KG, Yang EY, Longaker MT, Adzick NS. Wound size and gestational age modulate scar formation in fetal wound repair. J Pediatr Surg 1997;32(3):411-415

16 Efimov EA. Comparison of healing of full-thickness wounds in newborn and sexually mature rats. Bull Exp Biol Med 1968;65(6): 661-663

17 Adzick NS, Harrison MR, Glick PL, et al. Comparison of fetal, newborn, and adult wound healing by histologic, enzyme-histochemical, and hydroxyproline determinations. J Pediatr Surg 1985;20(4):315-319

18 Viljanto J, Raekallio J. Wound healing in children as assessed by the CELLSTIC method. J Pediatr Surg 1976;11(1):43-48

19 Coelho-Lemos IC, Campos AC, de Almeida M, et al. In utero malnutrition influences wound healing of newborn rats as measured by tensile strength and collagen deposition. JPEN J Parenter Enteral Nutr 2004;28(4):241-244, discussion 245

20 Babuccu O, Kalayci M, Peksoy I, Kargi E, Cagavi F, Numanoğlu G. Effect of cerebrospinal fluid leakage on wound healing in flap surgery: histological evaluation. Pediatr Neurosurg 2004;40(3): 101-106 